\title{
SUSTAINABILITY CONCEPT IN TURKISH SHIPYARDS
}

\author{
MEHMET TANTAN* \& HATİCE CAMGÖZ-AKDAĞ ${ }^{\dagger}$ \\ Department of Management Engineering, İstanbul Technical University, Turkey
}

ABSTRACT

Sustainability is an important issue in the 21 st century. Although there are a high number of publications, some areas are still untouched, like sustainability concepts in shipyards. This paper aims to explore the literature of the sustainability concept in the shipbuilding industry and to propose a further research outline. The impact of green supply chain practices (GSCM) on three sustainability performance - economic, environmental and social performance - will be also examined. A systematic literature review is applied between 1980 and 2020 using Scopus and Web of Science databases. After eliminating duplicates, unrelated articles, a total of 27 articles were identified. The analysis shows that there is not much research on the shipyard's sustainability and the green supply chain practices impact on the economic, environmental and social performance. One article examined the relations of green supply chain readiness, customer requirements, governmental involvement, social responsibility and competitive advantage to the willingness to participate in green supply chain management initiatives in the suppliers of two big shipyards. The other one examined which of the sustainable development goals collaborate with the maritime industry based on publicly published corporate social responsibility and sustainable development reports. Both studies do not focus on green supply chain practices as a performance evaluation of the three sustainable dimensions in a shipyard. In addition, there are dissertations in Turkey, which examined green supply chain practices and their impacts on the environmental, social and economic performance in the manufacturing, packaging companies, finding significance positive relations. As a result, we found that few studies examined the sustainability of shipyards, this study will fill the literature gap being one of the first study on this subject and contributing to the emerging shipyards sustainability literature.

Keywords: sustainability, shipbuilding industry, shipyard, green supply chain practices.

\section{INTRODUCTION}

Sustainability is defined in dictionary as "relating to, or being a method of harvesting or using a resource so that the resource is not depleted or permanently damaged" and "relating to a lifestyle involving the use of sustainable methods". With the growing concern about depleting the natural resources and thereby increasing environmental problems, the sustainability concept emerged as a critical and crucial set of development approaches to maintain and to develop the current average life quality of the current civilization.

The sustainability concept first emerged in Germany by Hans Carl von Carlowitz, who was originally a German tax accountant and mining administrator in Freiburg in 1713. One of his responsibility was to supply enough timber to the mining industry. The melting process of ores had consumed the whole forest nearby. Although the surroundings rivers coengineered and timbers were transported from long distance, the timber crises had only postponed for a while. Scarcity of timber and increasing transport costs had caused to bankruptcy in the mining sector. Under these circumstances, he formulated the first concept of sustainability in the forestry sector as Nachhaltigkeit in his book named "Sylvicultura oeconomica" or "Haußwirthliche Nachricht und Naturmäßige Anweisung zur wilden BaumZucht" in 1713 (Grober [1]).

\footnotetext{
* ORCID: https://orcid.org/0000-0002-1315-4653
}

† ORCID: https://orcid.org/0000-0002-9818-6012 
Industrial revolution started in the late eighteenth century in Europe, the extraordinary technological development, new inventions changed completely the life style in the world. Ninetieth century was transition phase from agriculture life style to the industrial life style. In the twentieth century, with the critical decision from coal driven engines to the petroleum based products driven engines, the increase in population led a spike in the production and indirectly the consumption of finished products and natural resources. Waste and depleting natural resources became two of some undesirable effects of the modern civilization. Emerging improvements like environmental preventive and corrective actions, efficiency defined as using less input and giving less waste and more output, new inventions in the ecofriendlier technologies were main common concerns in the mid of the twentieth centuries.

Consequently, United Nations has introduced the Brundtland Report to the public in order to take attention for the sustainable development in 1987. In this report sustainable development defined as "a development that meets the needs of the present without compromising the ability of future generations to meet their own needs" (Brundtland [2]). Since the main cause of the problem above were the output of the industrial activities, the main spot focalized to the companies those forced by the civil, public and governmental stakeholders to apply environmental and after sustainability approaches. Then two questions came out. First which policies do the companies should pursue to arrive the desired and needed sustainability level? Second, how to define and measure the sustainability performance for a company? Sustainability performance has defined as the quantification of an organization's total performance based on performance indicators, which can include its policies, decisions, and actions creating economic, social and environmental results (Buyukozkan and Karabulut [3]).

Green supply chain management (GSCM) is a concept created over time after 1990s with the idea of eliminating environmental concerns under the concept of supply chain management (Srivastava [4]). Most organizations were starting to go green in their business as concern to environmental sustainability, the concept of GSCM arose as a new systematic approach and becoming an important factor for business activities (Abu Seman [5]). In addition, GSCM can be considered a relatively advanced management practice for manufacturers to improve their environmental performance (Zhu et al. [6]).

Green supply chain answers both questions and determines indicators for performance evaluation, arranges the relations between the company with its suppliers and customer under a sustainability concept. Since environmental issues and scarcity of resources are hindering to achieve sustainable performance, GSCM is the philosophy to optimize the performance in unfavorable conditions. This generates an advance towards sustainable development and leads to considerable cost reduction to some or even all of the enterprises involved (Mardani et al. [7]). Green et al. [8] found out that the adoption of GSCM practices by manufacturing organizations leads to improved environmental performance and economic performance, which impact positively operational performance and consequently organizational performance. In addition, Rao and Holt [9] stated that many organizations in the South East Asian region recognizes GSCM as a way to demonstrate their sincere commitment to sustainability. The analysis identified that greening the different phases of the supply chain leads to an integrated green supply chain, which ultimately leads to competitiveness and economic performance. Yildiz Çankaya and Sezen [10] examined the impact of eight GSCM's practices on the on economic, environmental and social performance, which are the three dimensions of corporate sustainability. The study has been done in the 281 manufacturing firms in Turkey. The eight practices were green purchasing, green manufacturing, green distribution, green packaging, green marketing, environmental education, internal environmental management and investment recovery. Except for green 
purchasing, all GSCM dimensions are found to be related with at least one of the sustainability performance dimensions. As a result, GSCM has gradually become the new concept for the sustainable development of the enterprises.

In a supply chain, the interaction between the stakeholders consists of exchanging information and goods. The goods exchange includes transportation. Maritime transport remains the backbone of global supply chain, as more than four fifths of world merchandise trade by volume is carried by sea. Around 95,000 ships transported 11 billion tons of goods in 2019. Since environmental sustainability has become a major policy concern in global maritime transport, regulations are increasingly affecting shipping market dynamics that impacts on shipbuilding and shipyards, as they are responsible for incorporating new standards into the design and construction of ships (UNCTAD [11]).

Concerns about to construct more green and/or sustainable ships in order to achieve desired sustainability performance goals became stakeholders interest in the maritime industry, as well as in the shipyards that is a subsector in maritime industry. In that case, green supply chain management can assist the maritime sector to comply with IMO regulation and achieve the sustainability goals which benefits the society and future generation (Lister et al. [12]).

The studies examining the effects of GSCM practices on the three dimensions of sustainability (economic, environmental and social) in the shipyards are very rare, as well as in Turkey. Since sustainable development is very popular research field, there are few studies in maritime and especially in shipyards' sustainability. Therefore, this study aims to summarize the literature about sustainability and shipyards, and to give a clear outline for the next study.

Systematic review methodology has been explained in the second section. Section 3 presents the list of publications in a categorized table, and provide an analyses of the review. The last section contains conclusion with future ongoing research outline.

\section{LITERATURE REVIEW}

The research phases are described in Table 1. The search assumptions, limits and coverage have been determined in the first phase. Scopus and Web of Science databases have been selected for the research. The search variables were following; the time interval was from 1980 to 2020, documents types limited to articles and review written in English. The keywords were determined as "sustain*, green, shipyard, shipbuilding" in the article title, abstract and keywords areas of the searched document. The keyword sustain* is expressly used in order to cover different version of the word of "sustain", such as sustain, sustainability, sustainable, sustained, sustaining, etc. The word green may cover the literature for several version of green supply chain studies and therefore it is selected as a keyword. The shipyard and shipbuilding are two words related each other and were used alone or together in the searched documents.

The second phase includes the search execution. The Boolean operators "and" and "or" were used to combine searches. Two searches have been done in each database. First search in Scopus database was with the keywords "sustain* or green and shipyard", resulted in 151 articles. The similar keywords but with shipbuilding has resulted to 287 articles. When the Scopus combined two searches, total articles arrived to 362. On the other hand, first search in Web of Sciences database resulted over one million results with keywords "sustain* or green". This result shows how the subject is popular in the research area. However, refining the existing search with shipyard or shipbuilding decreased to 96 articles which is an explicit proof that there is a gap in this area. The endnote software was used to combine the two subtotal searches where 458 articles remained. 
Table 1: Research phases.

\begin{tabular}{|c|c|}
\hline Phases and descriptions & Details \\
\hline $\begin{array}{l}\text { Phase } 1 \\
\text { Defining the keywords and } \\
\text { search criteria }\end{array}$ & $\begin{array}{l}\text { Keywords: sustain*, green, shipyard, shipbuilding } \\
\text { Fields: Topics (article title, abstract, keywords) } \\
\text { Databases: Scopus and WoS } \\
\text { Time period: } 1980-2020 \\
\text { Document type: Article and Review } \\
\text { Language: English }\end{array}$ \\
\hline $\begin{array}{l}\text { Phase } 2 \\
\text { Executing the search }\end{array}$ & $\begin{array}{l}\text { Scopus } \\
\text { Search 1: "sustain* or green and shipyard" } \mathrm{n}=151 \\
\text { Search 2: "sustain* or green and shipbuilding" } \mathrm{n}=287 \\
\text { Combining } \# 1 \text { and } \# 2 ; \mathrm{n}=362 \\
\text { WoS } \\
\text { Search 1: "sustain* or green" } \mathrm{n}=1.011 .669 \\
\text { Search 2: refining "shipyard or shipbuilding" } \mathrm{n}=96 \\
\text { Total } \mathrm{n}=458\end{array}$ \\
\hline $\begin{array}{l}\text { Phase } 3 \\
\text { Screening the results }\end{array}$ & $\begin{array}{l}\text { Screens } \\
\text { Duplicates } x=84 \text { excluded } \\
\text { Eligibility check via title and abstract } x=307 \text { excluded } \\
\text { Available to download full text } x=40 \text { excluded } \\
\text { Remained full text } n=27\end{array}$ \\
\hline $\begin{array}{l}\text { Phase } 4 \\
\text { Reporting and dissemination }\end{array}$ & $\begin{array}{l}\text { Reading available full text } \\
\text { Creating Excel datasheet } \\
\text { Simultaneous data analyses } \\
\text { Reporting elaboration } \\
\text { Conceptual framework }\end{array}$ \\
\hline
\end{tabular}

The deeper analysis started in the third phase. Endnote excluded 84 duplicated articles. Then each articles have been checked within the title and abstract for eligibility, and subject areas. Arts and Humanities, Agricultural and Biological Sciences, Chemistry, Medicine, Chemical Engineering and Biochemistry, Genetics and Molecular Biology have been excluded. Total remained articles were 27 after eliminating articles without full contents.

\section{ANALYSES OF THE RESULTS}

China and South Korea are leading researches in Asia region whereas the shipbuilding seen as a driving developing growth factor of those economies and folllowed by Spain, Turkey and Holland from Europe. Since there are few studies in America region, it can be stated that shipbuildng sector is mainly located in Asian and Europe countries. Although the search started from 1980, but the first two findings are dated to 2008, followed a slight increase in publications (Fig. 1).

The articles are summarized in four categories; shipbuilding, maritime, shipbreaking and various. The field in fact is very large, and there are many related but discrete areas. Shipyards are the production facilities where the shipbuilding operations are performed. Ships coming out from shipyards sail naval routes, visit portes, transport human and trade goods, catch fish, purchasing consumables, spare parts, carburants and as a result create a huge economical activity which we can defined as maritime industry. Some unlucky ships sink and stay on the bottom sea level, very rare ships continue their life as a museum or school ship but most of 


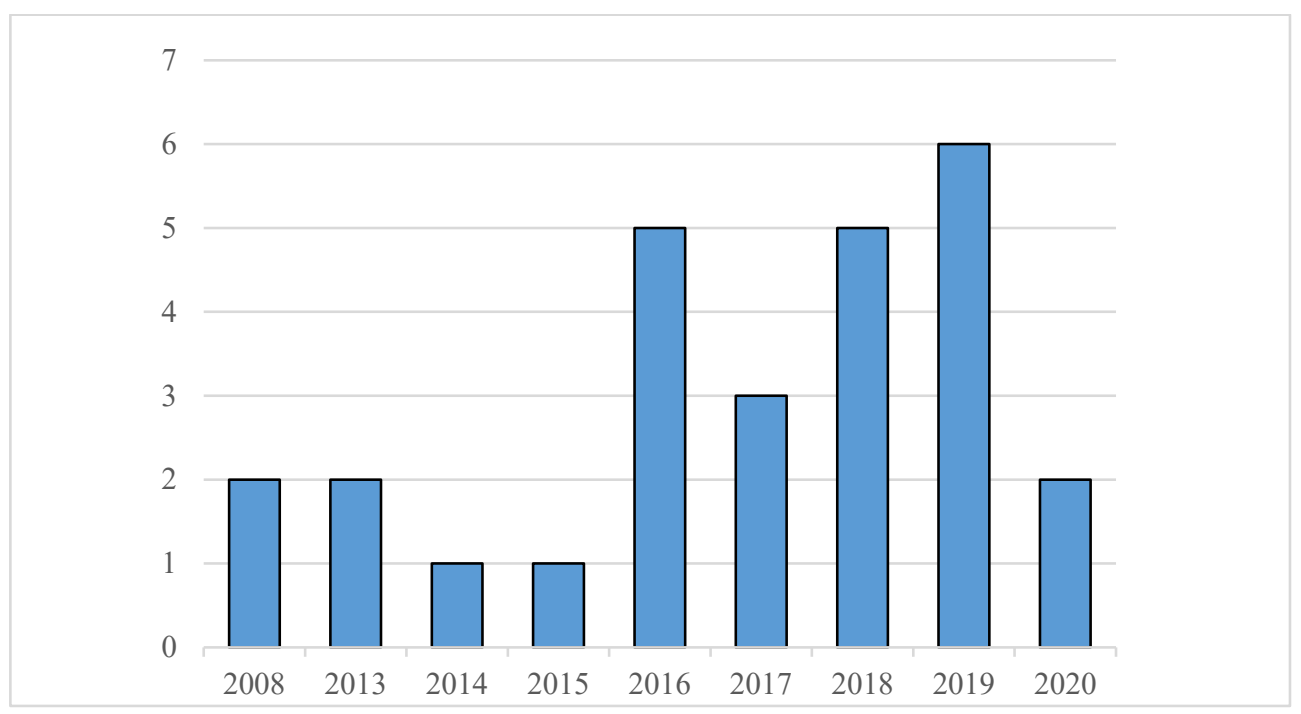

Figure 1: Annually published articles.

them go to the shipbreaking facility where the ship is completely broken in small parts for resell and recycle. The remaining two articles, in different subjects and not related with one of the above ones summed in the category named various. Focus area and methodology of each article is summarized in Table 2.

Shipyard layout design according green field project, sustainable growth directions for small and medium shipyards, the ways to improve the sustainabilty in the shipbuilding supply chain, green shipping and green manucturing in the shipyard workshop are main focus areas in the shipbuilding category. In addition, the articles in the maritime category focused customer requirement based sustainable maritime supply chain, noise effect of few ports in the mediterrean, review and analyse of green matimie environmental program in North America, the relationship between drivers and practices of the green maritime supply chain, using fiber reinforced polymers from the circular economy perspective and potential collaborations of the sustainable development goals in the maritime industry. The shipbreaking articles reviewed the environmental, economic, social, legal and tehnical aspects of shipbreaking and also greening the sector.

Authors used some methodologies such as review of the literature, case study, hypothesis testing via survey, data development analysis, establishing a framework, Artificial Neural Network, Monte Carlo analysis, Delphi method, Quality Function Deployment, emprical study in the articles. Findings are explained below, respectively.

Sanderson and Cox [13] examined the dichotomy of deciding either lean or agile approach is less useful in a shipbuilding supply chain environment and stated the design and build process used in the shipyard introduces radical unpredictability into the demand for "functional" components of naval vessels. Song and Woo [14] used the green field project for an efficient and assembly oriented shipyard layout design and followed by Lee et al. [15]. Lee [16] proposed directions to the small and medium sized shipyards such as; merger and acquisition, to switch activity from building to repair and maintenance, penetrating shipbreaking sector and establishing subcontractor links with the major shipyards for a 


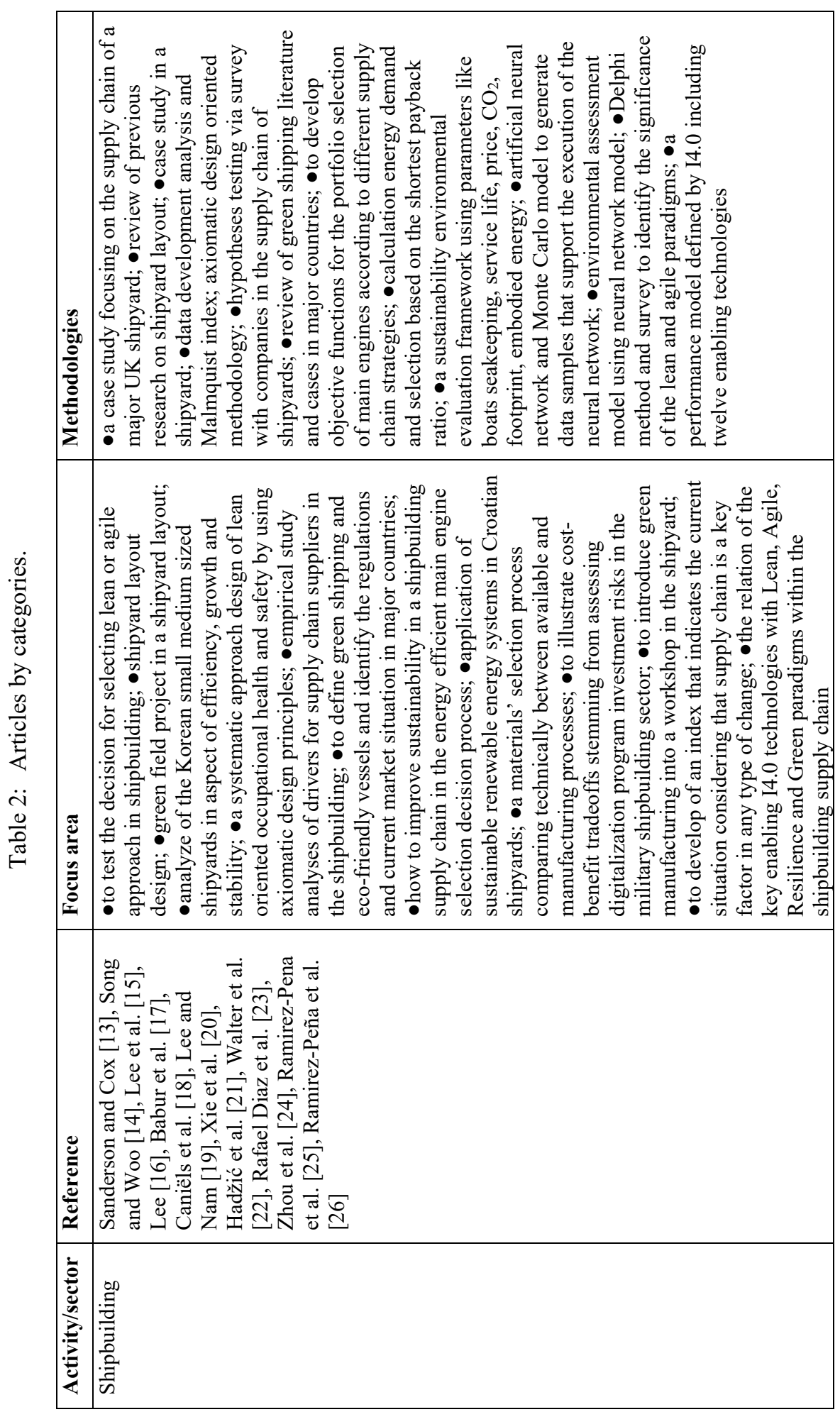

WIT Transactions on Ecology and the Environment, Vol 241, (c) 2020 WIT Press www.witpress.com, ISSN 1743-3541 (on-line) 


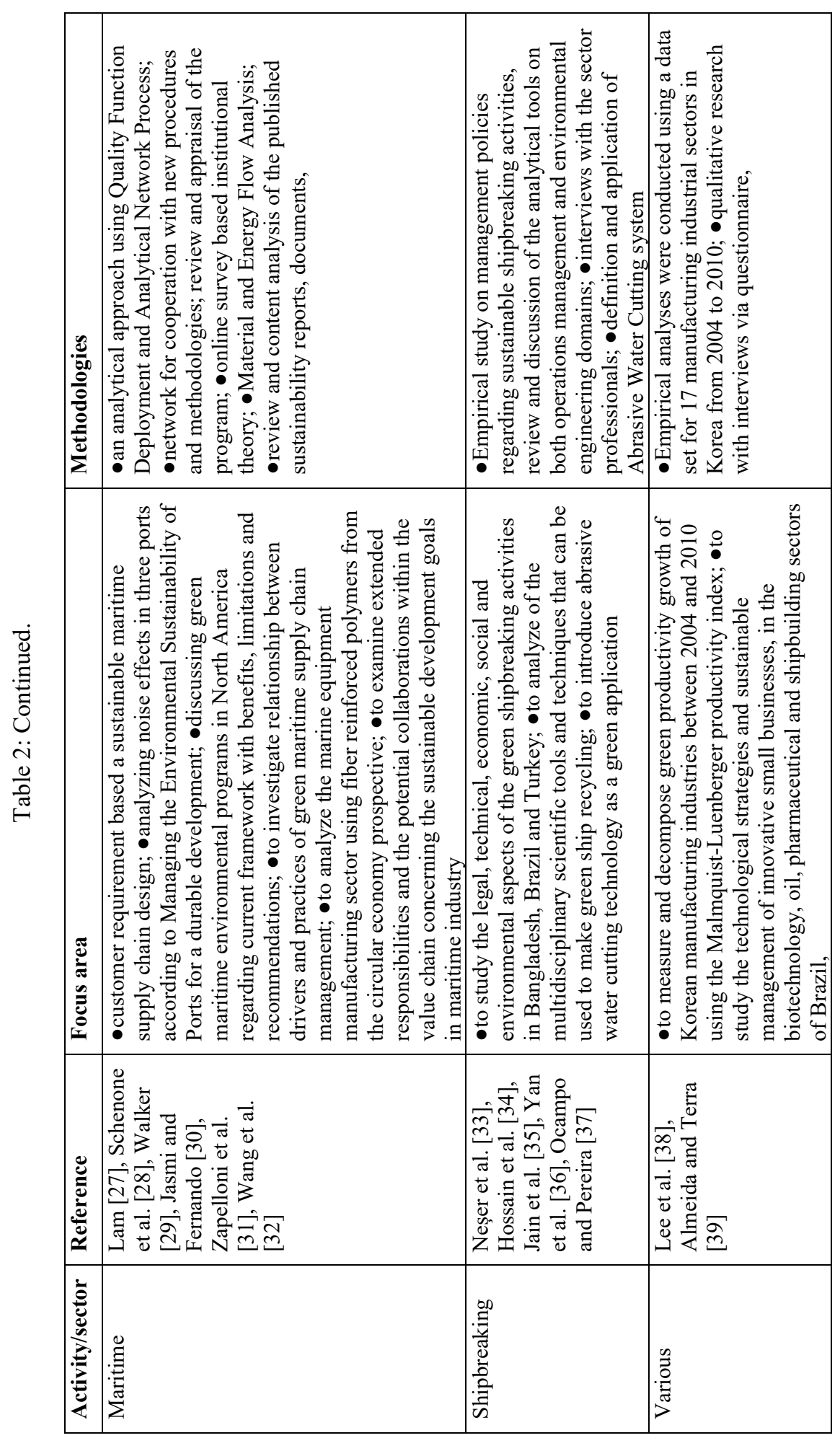


sustainable development. Babur et al. [17] designed a lean oriented axiomatic occupational health and safety system and applied in a shipyard. Green supply chain readiness, competitive advantage, and social responsibility are significant drivers in supplier participation. But governmental involvement and customer requirements are not significant (Caniëls et al. [18]). Lee and Nam [19] proposed four countermeasures to enhance strategic plans for green shipping in South Korea; the establishment of a shipping-shipbuilding collaborative network, information sharing and joint cost reduction for shipping and shipbuilding industry, investment in R\&D in eco-friendly vessels, support for LNG fueled ship. Technological innovations should be cost effective for an energy efficiency of main engine and a sustainable improvement (Xie et al. [20]). Solar panels are considered as the most suitable and sustainable technology (Hadžić et al. [21]). Gaining wood durability, adopting alternative native wood or wood cored sandwich composites may be a solution to enhance the artisanal boatyard's sustainability (Walter et al. [22]). Rafael Diaz et al. [23] proposed a framework to quantify benefits and risks per project thereby regarding the constraint within the project. Dust pollution, noise pollution and harmful gas pollution have been found the main pollutant sources in the shipyard workshop environment (Zhou et al. [24]). Ramirez-Pena et al. [25], [26] found lean and green paradigms the most implemented in the supply chain, green supply chain connects the social aspects required by the I4.0 performance model.

Lam [27] found the use of green design ships, engines and machinery were the most important design requirements in sustainable maritime supply chain. Schenone et al. [28] studied the impact of environmental noise generated from ports. Since the noise decreasing not possible in Patras port, soundproof windows installation is preferred, whereas in Tripoli port necessary improvements are taken to decrease noise level. The maritime companies in North America developed Green Maritime Environmental Program that proposed a framework to establish and reduce environmental impact. Participants demonstrate annual improvement of specific environemental performance indicators (Walker [29]). Jasmi and Fernando [30] determined support of top management is significantly related to the green supply chain solutions, whereas regulations, green initiatives, security are partially related. Zapelloni et al. [31] analysed the marine equipment manufacturing sector using fibre reinforced from the circular economy prospective to identify sustainable solutions for the manufacturing process stage. Sustainable development goals number 8 (Decent work and economic growth), 9 (Industry, innovation and infrastructure), 12 (Responsible consumption and production) and 14 (Life below water) are found the most aligned with the core business of the maritime industry, representing its core responsibility towards sustainability (Wang et al. [32]).

Neşer et al. [33] studied the environmental, safety and health problems in Turkish shipbuilding sector. The paper stated the distinction in regulation between developped and developing countries. Hossain et al. [34] stated grave environmental pollution, and its impact on marine ecosystems, biodiversity, forestry, fisheries and human health are the main obstacles for the development of a sustainable ship-breaking industry. Jain et al. [35] proposed material flow analysis to better manage waste and resources, thereby attracting green ship recycling. Abrasive water jet cutting is a green technology, increasing the economic value of scrap metal, decreasing environmental and labor health problems with high initial investment cost (Yan et al. [36]). Brazil shipyards need to acquire expertise and expand feasibility studies to develop a sustainable ship recycling industry (Ocampo and Pereira [37]).

Lee et al. [38] found the efficiency of total emissions is higher than that of direct emissions except for the shipbuilding industry. Almeida and Terra [39] presented that the innovation context can influence the development of enterprises, through a variety of factors, such as 
the institutional environment, the characteristics of the economic sector, sustainability management and established networks that affect the decision making and growth of the companies.

\section{THE TURKISH EXPERIENCE}

There are several written academic dissertations about green supply chain practices and its relation on the company performance in Turkey. Dilşad Güzel [40] investigated the relationship between supply chain integration, green supply chain implementations and business performance of 102 packaging manufactures in Marmara region. It was observed that supply chain integration affected green supply chain implementations and green supply chain implementations affected business performance.

Küçükoğlu [41] examined Turkish companies which are listed among ISO 500 companies for last 3 years and have ISO 14001 Environmental Management Certificate from sustainability and green innovation point of view. Green innovation activities have an important relation with a company's environmental performance, competitive advantage and sustainability.

Yildiz Çankaya and Sezen [10] searched the effect of green supply chain management practices on three important elements of corporate sustainability being environmental, economic, and social performance within 281 different companies including automotive, electronics and chemistry sectors. Green production, green transport and packaging were found to have positive performance effect on the three sustainability dimensions and others have positive effect on one or two dimensions.

One of the green supply chain practice, green logistic is seemed to increase economic, operational and environmental performance of health enterprises in Istanbul (Yanginlar [42]). Similarly, Dizaji [43] analyzed green marketing strategies and its effect on the performance in food manufacturing companies in Istanbul. Green marketing, green supply chain and green innovation are found significant for the business performance. Derya Öztürk [44] made nearly same study but with the food packaging companies in the TR83 Region of Turkey. In this study, green purchasing, green production and green packaging found to have positive effect on the business performance. Günday [45] found that green supply chain practices have positive effect on the business performance in the chemistry sector.

\section{CONCLUSION}

As seen in the previous sections, there are not many studies related with sustainability of the shipyards. Caniëls et al. [18] examined the relations of green supply chain readiness, customer requirements, governmental involvement, social responsibility and competitive advantage to the willingness to participate in green supply chain management initiatives in the suppliers of two big Dutch shipyards. In a different study, Wang et al. [32] examined which the sustainable development goals collaborate with the maritime industry based publicly published the corporate social responsibility and sustainable development reports. Both studies do not focus green supply chain practices as a performance evaluation of the three sustainable dimensions. Neither or nor used the shipyards as a research sample.

The shipyards operate in an international and highly competitive market. In order to keep the existing market share and to penetrate new markets, they should adapt new approaches, update marketing strategies, invest new technologies and innovations. Green supply chain practices and sustainability dimensions can help shipyards to create and apply a strategy in order to meet the goal described above. Turkish shipyards have basic knowledge about sustainability concept, mainly about environmental dimension, this is a constraint and also a challenge to develop for the shipyards. 
As a result, there is a gap in the shipyards and their sustainability performance in Turkish shipyards. Therefore, this study will aim to fill this gap by focusing the GSCM practices and their impacts on the economic, environmental and social performance of the shipyards. The result will contribute to the emerging literature in the shipyard sustainability by increasing the awareness level of sustainability among the executives

Further research will continue about the green supply chain practices and developing hypotheses with research model. In the literature, researchers used several green supply chain practices, but the authors think to consider green design, green purchasing, green production, green marketing, investment recovery, environmental management system and recycling in this study. Some practices like green packaging is not suitable in shipbuilding industry and omitted from the list.

It is difficult to obtain data since there is not publications and statistics. Therefore, the authors planned to demand to the Turkish Shipbuilder Association its cooperation, especially in the survey phase. In order to obtain accurate data, overcome any prejudice and increase awareness, the authors decided to make face to face survey.

After validation of the methodology and hypotheses, the questionnaire will be applied on the high-level managers of shipyards. Medium and big sized Turkish shipyards are mainly located in the eastern Marmara region of Turkey in several dedicated shipyards zone established by the government. So, the targeted sample population is not fragmented regionally. The results of the quantitative analyses will be presented in the next year.

\section{ACKNOWLEDGEMENT}

This paper is derived from a Doctoral thesis which is under progress in the Department of Management Engineering, Institute of Science, Istanbul Technical University.

\section{REFERENCES}

[1] Grober, U., Der Erfinder der Nachhaltigkeit. Zeit Online, Hans Carl von Carlowitz, 1999.

[2] Brundtland, H., Report of the World Commission on Environment and Development: Our Common Future, United Nations, 1987.

[3] Buyukozkan, G. \& Karabulut, Y., Sustainability performance evaluation: Literature review and future directions. J. Environ. Manage., 217, pp. 253-267, 2018. https://doi.org/10.1016/j.jenvman.2018.03.064

[4] Srivastava, S.K., Green supply-chain management: A state-of-the-art literature review. Int. J. Manag. Rev., 9, pp. 53-80, 2007. https://doi.org/10.1111/j.1468-2370.2007.00202.x.

[5] Abu Seman, N.A., Green supply chain management: A review and research direction. International Journal of Managing Value and Supply Chains, 3, pp. 1-18, 2012. https://doi.org/10.5121/ijmvsc.2012.3101.

[6] Zhu, Q., Gollagher, M., Geng, Y., Fujita, T. \& Hashimoto, S., Green supply chain management in leading manufacturers. Manag. Res. Rev., 33, pp. 380-392, 2010. https://doi.org/10.1108/01409171011030471.

[7] Mardani, A., Kannan, D., Hooker, R.E., Ozkul, S., Alrasheedi, M. \& Tirkolaee, E.B., Evaluation of green and sustainable supply chain management using structural equation modelling: A systematic review of the state of the art literature and recommendations for future research. Journal of Cleaner Production, 249, 2020. https://doi.org/10.1016/j.jclepro.2019.119383. 
[8] Green, K.W., Zelbst, P.J., Meacham, J. \& Bhadauria, V.S., Green supply chain management practices: Impact on performance. Supply Chain Manag., 17, pp. 290305, 2012. https://doi.org/10.1108/13598541211227126.

[9] Rao, P. \& Holt, D., Do green supply chains lead to competitiveness and economic performance? Int. J. Oper. Prod. Man., 25, pp. 898-916, 2005.

https://doi.org/10.1108/01443570510613956.

[10] Yildiz Çankaya, S. \& Sezen, B., Effects of green supply chain management practices on sustainability performance. Journal of Manufacturing Technology Management, 30, pp. 98-121, 2019. https://doi.org/10.1108/jmtm-03-2018-0099.

[11] UNCTAD, Review of Maritime Transport, UNCTAD/RMT/2019/Corr.1, United Nations, 2020.

[12] Lister, J., Poulsen, R.T. \& Ponte, S., Orchestrating transnational environmental governance in maritime shipping. Global Environ. Chang., 34, pp. 185-195, 2015. https://doi.org/10.1016/j.gloenvcha.2015.06.011.

[13] Sanderson, J. \& Cox, A., The challenges of supply strategy selection in a project environment: evidence from UK naval shipbuilding. Supply Chain Manag., 13, pp. 16-25, 2008. https://doi.org/10.1108/13598540810850283.

[14] Song, Y.J. \& Woo, J.H., New shipyard layout design for the preliminary phase and case study for the green field project. International Journal of Naval Architecture and Ocean Engineering, 5, pp. 132-146, 2013. https://doi.org/10.3744/Jnaoe.2013.5.1.132.

[15] Lee, S.J., Woo, J.H. \& Shin, J.G., New business opportunity: Green field project with new technology. International Journal of Naval Architecture and Ocean Engineering, 6, pp. 471-483, 2014. https://doi.org/10.2478/Ijnaoe-2013-0193.

[16] Lee, J.-S., Directions for the sustainable development of Korean small and medium sized shipyards. The Asian Journal of Shipping and Logistics, 29, pp. 335-360, 2013. https://doi.org/10.1016/j.ajsl.2013.12.003.

[17] Babur, F., Cevikcan, E. \& Durmusoglu, M.B., Axiomatic design for lean-oriented occupational health and safety systems: An application in shipbuilding industry. Computers and Industrial Engineering, 100, pp. 88-109, 2016. https://doi.org/10.1016/j.cie.2016.08.007.

[18] Caniëls, M.C.J., Cleophas, E. \& Semeijn, J., Implementing green supply chain practices: An empirical investigation in the shipbuilding industry. Maritime Policy and Management, 43, pp. 1005-1020, 2016. https://doi.org/10.1080/03088839.2016.1182654.

[19] Lee, T. \& Nam, H. A study on green shipping in major countries: In the view of shipyards, shipping companies, ports, and policies. Asian J. Shipping Log., 33, pp. 253-262, 2017. https://doi.org/10.1016/j.ajsl.2017.12.009.

[20] Xie, G., Yue, W.Y. \& Wang, S.Y., Energy efficiency decision and selection of main engines in a sustainable shipbuilding supply chain. Transport Res. D.-Tr. E., 53, pp. 290-305, 2017. https://doi.org/10.1016/j.trd.2017.04.022.

[21] Hadžić, N., Kozmar, H. \& Tomić, M., Feasibility of investment in renewable energy systems for shipyards. Brodogradnja, 69, pp. 1-16, 2018. https://doi.org/10.21278/brod69201.

[22] Walter, Y., Junior, W.K. \& da Silva, F.P., Accessing small craft's boatbuilding sustainability: A materials selection chart's approach. Materialwissenschaft Und Werkstofftechnik, 49, pp. 1409-1416, 2018. https://doi.org/10.1002/mawe.201700245. 
[23] Rafael Diaz, K.S., Landaeta, R. \& Padovano, A., Shipbuilding supply chain framework and digital transformation: A project portfolios risk evaluation. International Conference on Industry 4.0 and Smart Manufacturing, 2019.

https://doi.org/10.1016/j.promfg.2020.02.067.

[24] Zhou, W., Wang, J. \& Zhu, X., Research on environmental assessment model of shipyard workshop based on green manufacturing. Journal of Coastal Research, 94, pp. 16-20, 2019. https://doi.org/10.2112/Si94-004.1.

[25] Ramirez-Pena, M., Abad Fraga, F.J., Sanchez Sotano, A.J. \& Batista, M., Shipbuilding 4.0 Index approaching supply chain. Materials (Basel), 12, 2019. https://doi.org/10.3390/ma12244129.

[26] Ramirez-Peña, M., Sánchez Sotano, A.J., Pérez-Fernandez, V., Abad, F.J. \& Batista, M., Achieving a sustainable shipbuilding supply chain under I4.0 perspective. Journal of Cleaner Production, 244, 2020. https://doi.org/10.1016/j.jclepro.2019.118789.

[27] Lam, J.S.L., Designing a sustainable maritime supply chain: A hybrid QFD-ANP approach. Transport Res. E-Log, 78, pp. 70-81, 2015. https://doi.org/10.1016/j.tre.2014.10.003.

[28] Schenone, C., Pittaluga, I., Borelli, D., Kamali, W. \& El Moghrabi, Y., The impact of environmental noise generated from ports: Outcome of MESP project. Noise Mapping, 3, pp. 26-36, 2016. https://doi.org/10.1515/noise-2016-0002.

[29] Walker, T.R., Green marine: An environmental program to establish sustainability in marine transportation. Mar. Pollut. Bull., 105, pp. 199-207, 2016. https://doi.org/10.1016/j.marpolbul.2016.02.029.

[30] Jasmi, M.F.A. \& Fernando, Y., Drivers of maritime green supply chain management. Sustainable Cities and Society, 43, pp. 366-383, 2018. https://doi.org/10.1016/j.scs.2018.09.001.

[31] Zapelloni, G., Garcia Rellan, A. \& Bello Bugallo, P.M., Sustainable production of marine equipment in a circular economy: Deepening in material and energy flows, best available techniques and toxicological impacts. Sci. Total Environ., 687, pp. 9911010, 2019. https://doi.org/10.1016/j.scitotenv.2019.06.058.

[32] Wang, X., Yuen, K.F., Wong, Y.D. \& Li, K.X., How can the maritime industry meet sustainable development goals? An analysis of sustainability reports from the social entrepreneurship perspective. Transportation Research Part D: Transport and Environment, 78, 2020. https://doi.org/10.1016/j.trd.2019.11.002.

[33] Neşer, G., Ünsalan, D., Tekoğul, N. \& Stuer-Lauridsen, F., The shipbreaking industry in Turkey: Environmental, safety and health issues. Journal of Cleaner Production, 16, pp. 350-358, 2008. https://doi.org/10.1016/j.jclepro.2006.08.018.

[34] Hossain, M.S., Fakhruddin, A.M., Chowdhury, M.A.Z. \& Gan, S.H., Impact of shipbreaking activities on the coastal environment of Bangladesh and a management system for its sustainability. Environmental Science and Policy, 60, pp. 84-94, 2016. https://doi.org/10.1016/j.envsci.2016.03.005.

[35] Jain, K.P., Pruyn, J.F.J. \& Hopman, J.J., Material flow analysis (MFA) as a tool to improve ship recycling, Ocean Engineering, 130, pp. 674-683, 2017. https://doi.org/10.1016/j.oceaneng.2016.11.036.

[36] Yan, H.S., Wu, L.Y. \& Yu, J.X., The environmental impact analysis of hazardous materials and the development of green technology in the shipbreaking process. Ocean Engineering, 161, pp. 187-194, 2018. https://doi.org/10.1016/j.oceaneng.2018.03.024. 
[37] Ocampo, E.S. \& Pereira, N.N., Can ship recycling be a sustainable activity practiced in Brazil? Journal of Cleaner Production, 224, pp. 981-993, 2019. https://doi.org/10.1016/j.jclepro.2019.03.173.

[38] Lee, S., Noh, D.W. \& Oh, D.H., Characterizing the difference between indirect and direct $\mathrm{CO}_{2}$ emissions: Evidence from Korean manufacturing industries, 2004-2010. Sustainability, 10, 2018. https://doi.org/10.3390/su10082711.

[39] Almeida, M. \& Terra, B., Technological strategies and sustainable management for small businesses in the Brazilian innovation context. Int. J. Innov. Sustain., 13, pp. 20 35, 2019.

[40] Dilşad Güzel, O.D., An investigation on the relationship among supply chain integration, green supply chain implementations and business performance. Sosyal Bilimler Enstitüsü Dergisi. 6, 2016.

[41] Küçükoğlu, M.T., Investigating Turkish companies from sustainability and green innovation perspective. Social Science Institute, Istanbul University, 2014.

[42] Yanginlar, G., The impact of green logistics on business performance: A research in healthcare enterprises. Graduate School of Social Sciences, Beykent University, 2015.

[43] Dizaji, B.S., Green marketing strategies in manufacturing operations, a model suggestion on relationship with performance. Social Science Institute, Ataturk University, 2017.

[44] Derya Öztürk, E.O., Effect of green supply chain practices on business performance: A case study of food-packaging sector in Region Tr83. Sosyal, Beşeri ve Idari Bilimlerde Akademik Çalışmalar, 2018.

[45] Günday, A.H., The impact of green supply chain applications on business performance: An empirical analysis in the chemical sector. Graduate School of Social Sciences: Selçuk University, 2018. 